\title{
Synaptic Mechanisms of Directional Selectivity in Ganglion Cells of Frog Retina as Revealed by Intracellular Recordings
}

\author{
Shu-ichi Watanabe and Motohiko Murakami \\ Department of Physiology, Keio University School of Medicine, \\ Shinjuku-ku, Tokyo, 160 Japan
}

\begin{abstract}
In order to analyze mechanisms of directional selectivity in retinal ganglion cells, synaptic potentials were recorded intracellularly in the eye-cup preparation of the bullfrog. Some preparations were perfused with tetrodotoxin to isolate the synaptic potentials from spike discharges. The cells were classified into ON-OFF-, ON-, and OFFtype by the responses to a stationary flashing light. About $40 \%$ of the cells in each type showed directional selectivity to a moving stimulus across their receptive fields. ON-OFF-type cells produced both EPSP and IPSP, and their amplitudes varied depending on the direction of stimulus movement. These findings suggest that the directional selectivity in ON-OFF-type cells could be attributed to the balance of counteracting postsynaptic potentials. On the other hand, ON- and OFF-type cells responded to the moving stimuli only with EPSP's, and no IPSP was detected. An EPSP evoked by the preferred movement of stimulus was larger in amplitude than that produced by the null movement, thus resulting in directional selectivity. The neural mechanism responsible for the difference in EPSP amplitude in ON- and OFF-type cells probably lies presynaptic to the ganglion cells.
\end{abstract}

Key Words: directional selectivity, frog retina, ganglion cell, tetrodotoxin.

It has been reported that some retinal ganglion cells respond with spike discharges to a movement of an object in the "preferred" direction across their receptive fields, whereas the opposite "null" movement evokes little or no spike. This property of the cells, called directional selectivity, has been found in a variety of animals, including frog (MATURANA et al., 1960; NorTON et al., 1970), mudpuppy (Werblin, 1970), turtle (Baylor and Fettiplace, 1979; Marchiafava, 1979; Jensen and DeVoe, 1983), rabbit (Barlow and Hill, 1963; Barlow et al., 1964; BARLOW and LeVICK, 1965; Oyster, 1968; Oyster et al., 1972; WyATT and DAW,

Received for publication October 24, 1983

渡辺修一，村上元彦 
1975; CALdwell et al., 1978), ground squirrel (Michael, 1968), pigeon (Holden, 1977), and cat (Cleland and Levick, 1974).

Most of these studies were made by extracellular recording of spike discharges from ganglion cells or optic nerve fibers. To study the mechanisms of directional selectivity in further detail, it is necessary to analyze synaptic potentials in ganglion cells. Some trials with this intention have been made in turtle (Marchiafava, 1979; Jensen and DeVoe, 1983) and in rabbit (DACHeux, 1977). MARChiafava (1979) has suggested that, in turtle ganglion cells, the directional selectivity can be attributed to the time sequence of generation of EPSP and IPSP. For example, in response to a target moving in the null direction, IPSP is generated prior to EPSP. The preceding IPSP hinders spike generation in ganglion cells.

To investigate whether this is the only mechanism of directional selectivity in all types of ganglion cells, we carried out intracellular recordings in bullfrog ganglion cells. In some of the experiments, postsynaptic potentials were recorded after spike discharges had been blocked by tetrodotoxin. The present results demonstrate that the hypothesis proposed by MARCHIAFAVA (1979) is applicable only to ON-OFF-type ganglion cells, and that the directional selectivity of ONand OFF-type cells is achieved in the neural network presynaptic to ganglion cells.

\section{METHODS}

Preparation and perfusion. Eye-cup preparations of the bullfrog, Rana catesbeiana, were used. After the frog had been dark-adapted for more than 1 $\mathrm{hr}$, the animal was decapitated and the eyes were enucleated. The anterior part of the eye was removed together with the lens, and the vitreous humor was drained off with pieces of tissue paper. All surgical operations were carried out under dim red light. The preparation was placed in a perfusion chamber (MURAKAMI et al., 1982) to which oxygenated Ringer solution was continuously supplied at a flow rate of about $1 \mathrm{ml} / \mathrm{min}$. The composition of the normal Ringer solution was (in mM): $\mathrm{NaCl} 106, \mathrm{KCl} 2.7, \mathrm{CaCl}_{2} 1.8, \mathrm{MgCl}_{2} 1.0, \mathrm{Na}_{2} \mathrm{SO}_{4} 1.8$, $\mathrm{NaHCO}_{3} 0.13$, glucose 10, and HEPES 3.0. The pH was adjusted to 7.8. The tetrodotoxin (TTX, 3.1 $\mu \mathrm{M}$ ) solution was made by dissolving TTX (Sankyo Co.) in the normal Ringer solution.

Intracellular recording. Glass micropipettes were filled with $4 \mathrm{M}$ potassium acetate (electrode resistance: 120-300 M $\Omega$ ) for intracellular recording, or with $5 \%$ horseradish peroxidase (HRP, Toyobo Co., Grade I-C) in $1 \mathrm{M} \mathrm{KCl}$ for intracellular staining. Ganglion cells were recorded at about $50 \mu \mathrm{m}$ from the internal limiting membrane. Responses were recorded with a preamplifier (Nihon Kohden Co., MEZ-8201) and displayed on an oscilloscope. They were also stored on FM magnetic tapes and later played back at reduced tape speed on a pen recorder (Nihon Kohden Co., RJG-4002). When necessary, responses were averaged by a signal averager (Nihon Kohden Co., ATAC-250). 


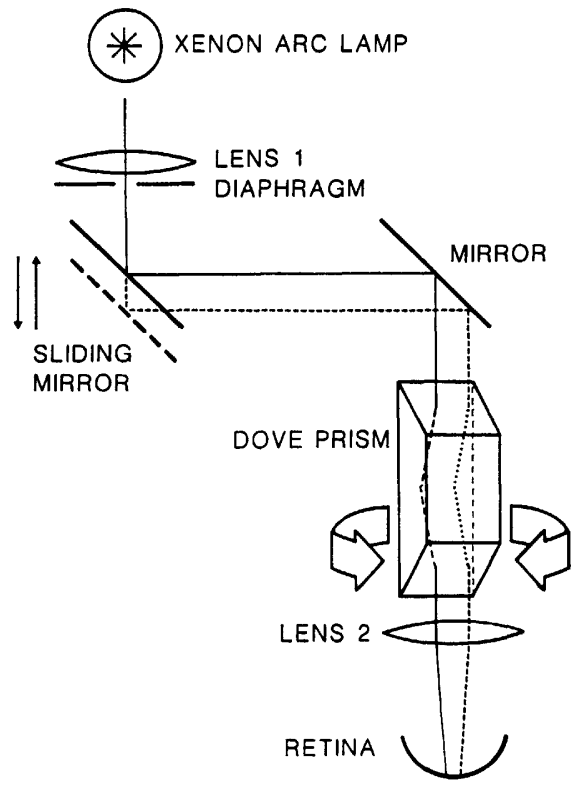

Fig. 1. Scheme of the principal part of the optical system used for stimulus movement. The light beam from the xenon short arc lamp is collimated by LENS 1 . The excursion of the image is $5.5 \mathrm{~mm}$ on the retina. Distortion of the image on the slope of the concave retinal surface was negligible within the receptive fields of the ganglion cells $(1.1 \mathrm{~mm}$, cf. Figs. 4 and 9).

To polarize the cell membrane, currents were applied through the recording electrode from a constant current source built in the preamplifier.

Cell identification. Some of the recorded cells were intracellularly stained by HRP injection after MARCHIAFAVA and WEILER (1982) for morphological identification. In all of the 10 cells stained, the axons were clearly recognized in the flat-mount preparations, and the cells were confirmed as ganglion cells.

Optical system. Figure 1 schematically shows a principal part of the optical system. The light beam was collimated, and a diaphragm having a slit aperture was inserted in the light path. The image of the slit focused on the retina was a white light bar $\left(3.5 \mathrm{~mm} \times 300 \mu \mathrm{m}\right.$, intensity: $\left.4 \mathrm{erg} \cdot \mathrm{cm}^{-2} \cdot \mathrm{sec}^{-1}\right)$. The light bar was moved back and forth perpendicularly to its long axis by sliding a surface mirror in the opposite directions, as indicated by straight arrows. The axis of the stimulus movement was determined by rotating a Dove prism at an appropriate angle, as indicated by round arrows. The stimuli were presented in $36^{\circ}$ steps of rotation.

In order to maintain the state of adaptation, diffuse background light was given throughout the experiment (white light, $0.25 \mathrm{log}$ unit less than that of the test light). 


\section{RESULTS}

Classification of ganglion cell types and directional selectivity

In total, 85 cells were studied: 25 ON-OFF-type, 19 ON-type, and 41 OFFtype cells classified according to HARTLINE's criteria (1938). The responses to a stationary flashing light spot (500 $\mu \mathrm{m}$ in diameter) consisted of synaptic potentials and action potentials (Fig. 2, left column). Most of the frog ganglion cells showed a few spike discharges, as has previously been reported (Tomita et al., 1961; NoRTON et al., 1970). Spike frequency was much lower in the presence of background light, as shown in Fig. 2.

Cells illustrated in Fig. 2 had directional selectivity; they responded with a few spikes to the preferred movement (middle column), but no spike was generated by the null movement (right column).

About $40 \%$ of each type of cells showed directional selectivity (Table 1); a result comparable with the percentage obtained by BowLING (1980) in the turtle retina. However, the above figure seems to be an underestimate, since many cells were lost before the completion of all test protocol for the directional selectivity.

Optimal velocities of the stimulus movement varied from cell to cell irrespective of the response types, but usually ranged from 1.7 to $4.2 \mathrm{~mm} \cdot \mathrm{sec}^{-1}$ on the

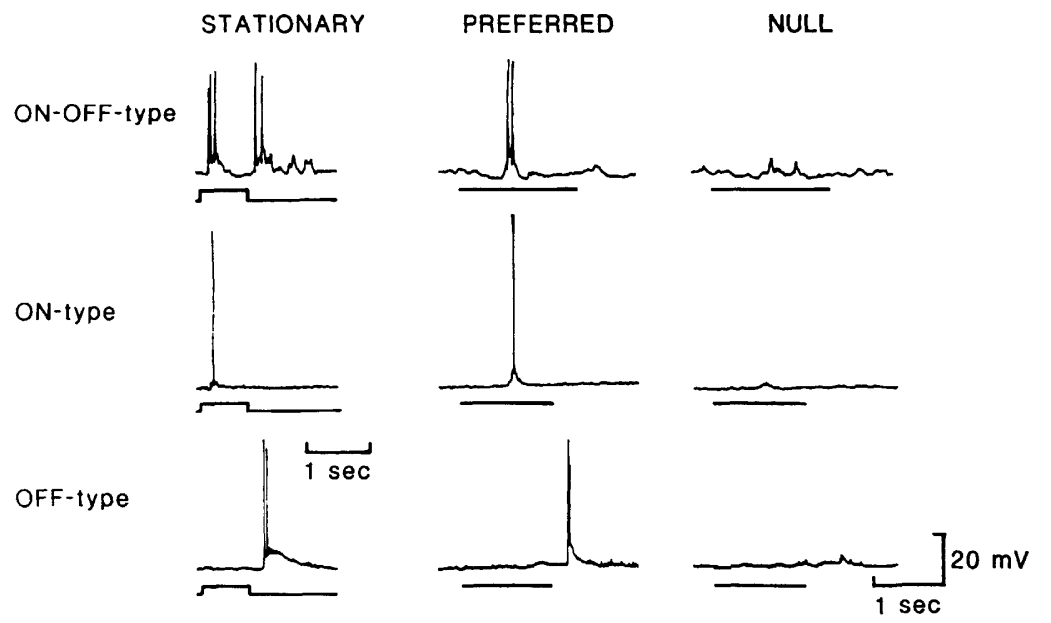

Fig. 2. Responses of ON-OFF-, ON-, and OFF-type directionally selective cells. Left column: responses to stationary spot $(500 \mu \mathrm{m}$ in diameter, $800 \mathrm{msec}$ in duration as indicated by the elevations of the lower traces attached to the records). Middle and right columns: responses to the moving light bar $(300 \mu \mathrm{m} \times 3.5 \mathrm{~mm})$ in the preferred and null directions. The velocities of bar movement are $3.2 \mathrm{~mm} \cdot \mathrm{sec}^{-1}$ for the ON-OFFtype cell, and $4.2 \mathrm{~mm} \cdot \mathrm{sec}^{-1}$ for the ON- and OFF-type cells. Since frequency characteristics of the pen recorder were not sufficient to follow the rapid time course of the spikes, the recorded spike amplitudes were about $85 \%$ of the full amplitude observed on the oscilloscope screen. 
Table 1. The population and percentage of the directionally selective ganglion cells.

\begin{tabular}{lcccc}
\hline Directional selectivity & ON-OFF-type & ON-type & OFF-type & Total \\
\hline Selective & 8 & 7 & 17 & 32 \\
Non-selective & 17 & 12 & 24 & 53 \\
\hline Total & 25 & 19 & 41 & 85 \\
$\%$ & 32 & 37 & 41 & 38 \\
\hline
\end{tabular}

A STATIONARY

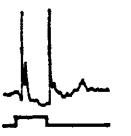

B

PREFERRED

NULL $+0.2 n$
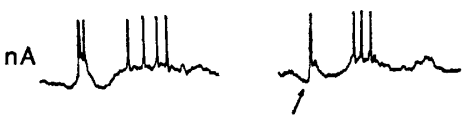

0<smiles>C=C(C)CCCCC</smiles>
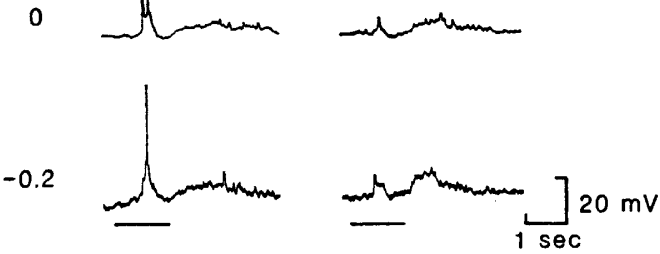

Fig. 3. Responses of a directionally selective ON-OFF-type cell. A: response to the stationary spot stimulus. B: the effects of polarization of cell membrane on the responses to moving light bar stimulus $\left(4.2 \mathrm{~mm} \cdot \mathrm{sec}^{-1}\right)$. The current intensities are indicated on the left of the records. The arrow attached to the record (B, NULL, +0.2 nA) indicates IPSP revealed by depolarization of the cell membrane.

retina. If the light bar was moved at a speed faster than the optimal, the cell responded only with small depolarizations, and no spike discharge was observed even to the preferred movement. Slower movement in either direction produced spikes superimposed on the slow potentials.

Directional selectivity in ON-OFF-type cell

The cell in Fig. 3 showed a typical ON-OFF-type response to the stationary flashing stimulus (Fig. 3A). The cell had a directional selectivity. Responding to the preferred movement (Fig. $3 \mathrm{~B}, 0 \mathrm{nA}$ ), the cell produced a large depolarization and spike discharges. When the stimulus left the receptive field, the cell 
showed another long-lasting depolarization (about $2 \mathrm{sec}$ ), which was smaller in amplitude than the preceding one. When the stimulus was moved in the null direction, no spike was elicited. Instead, only the synaptic potentials were observed. They were similar in shape to those evoked by the preferred movement, but of smaller amplitude. Difference between synaptic potentials evoked by stimulus movements in both directions became evident when the cell membrane was depolarized by injection of constant current (Fig. 3B, +0.2 nA); a particular difference was an initial large negative deflection (indicated by an arrow) in the response to the null movement. The negative deflection was suppressed when the membrane was hyperpolarized (Fig. 3B, $-0.2 \mathrm{nA}$ ). Absolute membrane potential values during current injection could not be estimated because the electrode showed a strong rectification. However, the above observation indicates that the initial negative deflection in response to the null movement is an IPSP which has a reversal potential negative to the resting potential. Under a depolarized condition (Fig. 3B, $+0.2 \mathrm{nA}$ ), the initial IPSP was also seen in response to the preferred movement, but it was small in amplitude and was counteracted by a following large EPSP. Hyperpolarization after the large EPSP indicates that the IPSP was continuously produced during the stimulus movement. Thus, it is concluded that the directional selectivity in ON-OFF-type cells is formed as a result of interaction between EPSP and IPSP occurring at the postsynaptic site of the ganglion cell.

\section{Asymmetrical receptive field organization of directionally selective ON-OFF-type cell}

Directionally selective ON-OFF-type cells had asymmetrical receptive fields. The cell in Fig. 4 showed directional selectivity to the moving stimulus (upper records). The lower records illustrate responses of this cell to a stationary flashing light bar given at various positions displaced from the center of the receptive field along the preferred-null axis. Plus signs $(+)$ indicate that the stimulus was presented at positions displaced towards the preferred direction, and minus signs $(-)$ indicate the positions displaced towards the null direction. When the stimulus was given at the center $(0 \mu \mathrm{m})$ or at $\pm 180 \mu \mathrm{m}$ positions, the cell gave rise to a typical ON-OFF-type response. At positions beyond $+360 \mu \mathrm{m}$, the responses during the stationary flash consisted only of an IPSP, and an action potential superimposed on depolarizing synaptic potentials was seen after the termination of the flash. On the contrary, at $-360 \mu \mathrm{m}$ position the cell showed only the depolarizing synaptic potentials and no IPSP.

In order to analyze the synaptic potentials in further detail, the responses elicited at each position of the receptive field were averaged by the signal averager, and the results were arranged vertically in Fig. 5 to make comparison easier. The initial response following the stationary stimulus onset was a hyperpolarization (i.e., IPSP) when the stimulus was presented at +540 and $+360 \mu \mathrm{m}$. Larger 


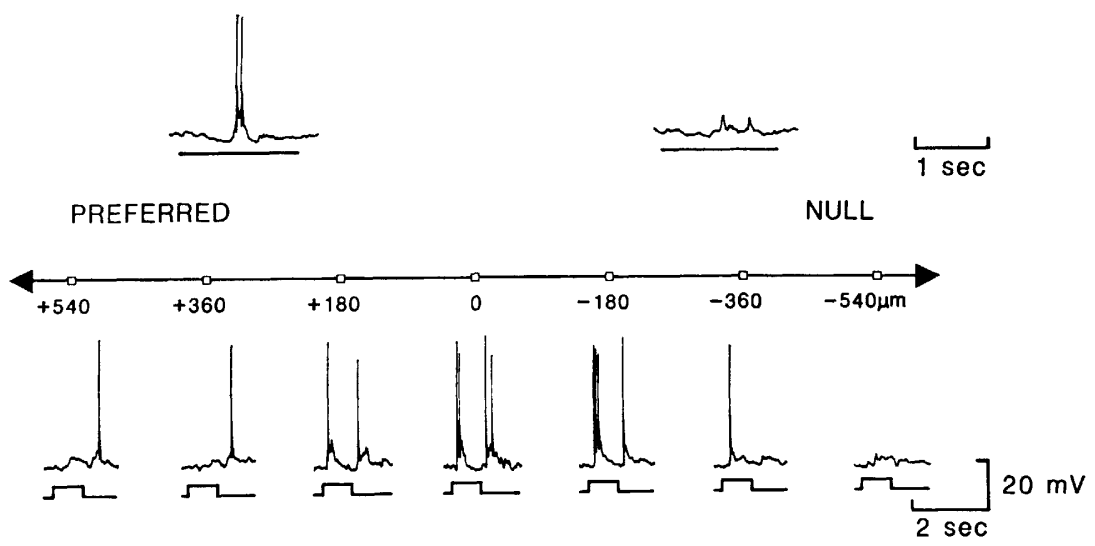

Fig. 4. Responses of a directionally selective ON-OFF-type cell. Upper records: responses to the moving light bar $\left(3.2 \mathrm{~mm} \cdot \mathrm{sec}^{-1}\right)$ in the preferred (left record) and in the null direction (right record). Lower records: responses to the stationary flashing bar stimulus ( $800 \mathrm{msec}$ in duration) presented at various positions in the receptive field along the preferred-null axis of directional selectivity. The positions of the stimulus are indicated by distances from the center of the receptive field with signs as + or - in respect to the preferred and null directions as shown on the middle scale.

initial hyperpolarizations were seen in response to the flash presented at +180 and $0 \mu \mathrm{m}$, but they were soon counteracted by large depolarizations (i.e., EPSP's) of short latencies (less than $120 \mathrm{msec}$ ). These observations again indicate the asymmetrical organization of the receptive field of ON-OFF-type cells.

It has been shown in the retinas of the rabbit (BARLOw and LEVICK, 1965) and the ground squirrel (MICHAEL, 1968), that the receptive field of the directionally selective cell consists of subunits which also have directional selectivity. In the present study, we examined whether this was also the case in the frog retina by moving the light bar for a short distance $(180 \mu \mathrm{m})$ within the receptive field. The result was quite variable even in the same cell; the preferred movement evoked spikes in some trials but not in others. It is therefore unlikely that the receptive field of the frog ganglion cell could be formed by summation of directionally selective subunits.

Symmetrical receptive field organization of directionally non-selective ON-OFFtype cell

Contrary to the directionally selective ON-OFF-type cells, the receptive field organization of non-selective cells was symmetrical. The cell in Fig. 6 produced similar responses to the moving stimulus in either direction along all axes tested (the upper records). The responses to the stationary flashing stimulus presented at various positions along an arbitrary axis were almost symmetrical on either side of the receptive field center (the lower records). 


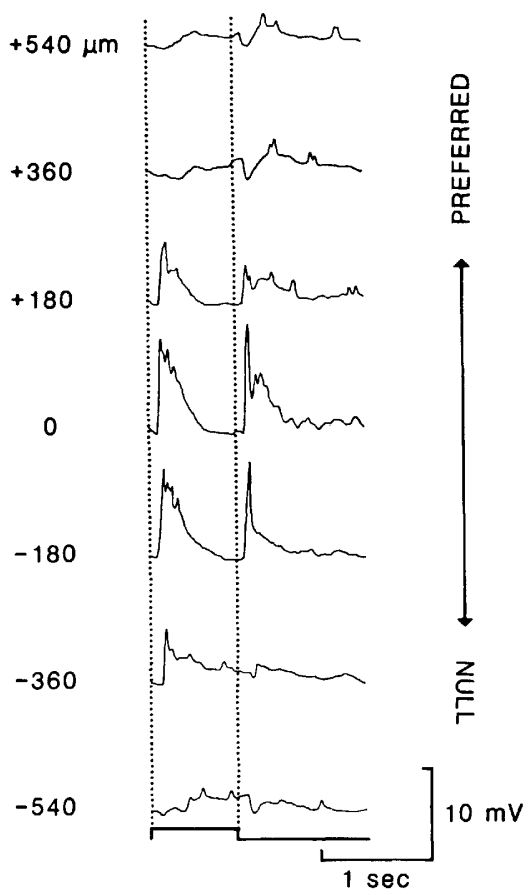

Fig. 5. Averaged responses of the directionally selective ON-OFF-type cell of Fig. 4 to a stationary bar stimulus presented at various positions in the receptive field. Eight responses at each position were averaged. Slow potentials were faithfully recorded but action potentials were lost because of a low sampling frequency of the averaging. The size and duration of the stimulus are the same as in Fig. 4.
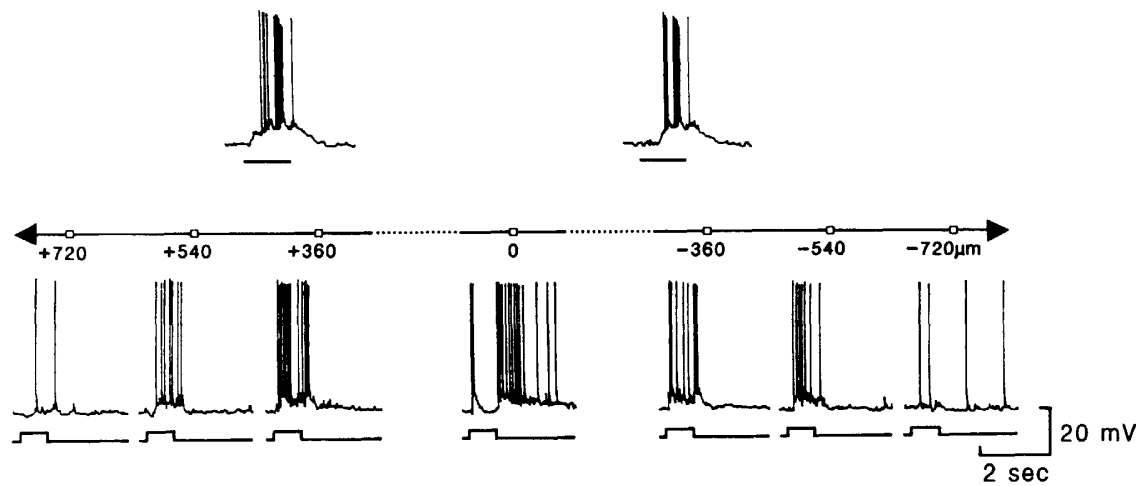

Fig. 6. Responses of a directionally non-selective ON-OFF-type cell. Upper records: responses to the moving bar stimulus $\left(4.2 \mathrm{~mm} \cdot \mathrm{sec}^{-1}\right)$. Lower records: responses to the stationary flashing bar stimulus presented at various positions in the receptive field. For further explanations, see Fig. 4. 


\section{Directional selectivity in ON-type cell}

Seven out of nineteen ON-type ganglion cells showed directional selectivity to the moving stimulus. The cell in Fig. 7 is an example. Different from directionally selective ON-OFF-type cells, this cell responded only with depolarizations to the stimulus moving in either direction (Fig. 7A). In both responses recorded in the control solution, differences in amplitude or in time course of synaptic potentials could not be clearly seen, since the response to the preferred movement was accompanied by spike discharges. When the preparation was perfused with the TTX solution $(3.1 \mu \mathrm{M})$, it became clear that the depolarizations in response to the preferred movement were larger in amplitude than those evoked by the null movement.

It is necessary to examine whether these synaptic potentials consisted of successively occurring EPSP's or they contained IPSP's, since BELGUM et al. (1982) reported that in the mudpuppy retina $\mathrm{ON}$ - and OFF-type ganglion cells receive both excitatory and inhibitory synaptic inputs. Therefore, cell membrane was polarized by injection of extrinsic currents through the recording electrode (Fig. 7B). The amplitude of the stimulus-induced depolarization was simply reduced

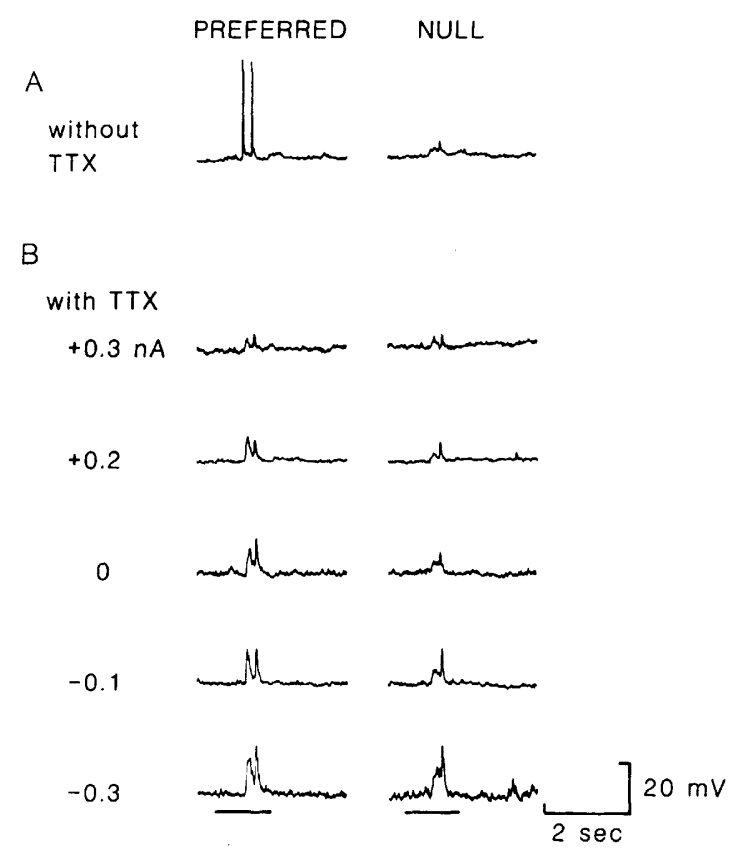

Fig. 7. Responses of a directionally selective $\mathrm{ON}$-type cell to a bar stimulus $\left(4.2 \mathrm{~mm} \cdot \mathrm{sec}^{-1}\right)$ moving in the preferred (left column) and in the null (right column) direction. A: responses recorded from the retina perfused with normal Ringer solution. B: effects of polarization of cell membrane on the responses recorded in the TTX-containing $(3.1 \mu \mathrm{M})$ Ringer solution. The intensity of polarizing current is indicated on the left of the records. 
when the membrane was depolarized $(+0.2$ and $+0.3 \mathrm{nA})$, while it was enhanced without any significant difference in the shapes and time courses when the membrane was hyperpolarized $(-0.1$ and $-0.3 \mathrm{nA})$. If the depolarizing response was caused by a reduction of hyperpolarizing IPSP (disinhibition) accompanied by a conductance decrease, it would be expected that a membrane hyperpolarization would suppress the "depolarizing" response. Therefore, no indication was detected in support of the above explanation for the "depolarizing" responses (see DISCUSSION).

\section{Directional selectivity in OFF-type cell}

A similar experiment on the directionally selective OFF-type cell is shown in Fig. 8. After the TTX application, the isolated EPSP's resembled spikes in this figure. However, they were not spikes, since their time course was much slower than that of a spike. Furthermore, when the stimulus intensity was reduced, their amplitudes decreased in graded manner as has been observed by MURAKAMI and SHIGEMATSU (1970).

A depolarization evoked by the preferred movement was larger than that evoked by the null movement (Fig. 8B, $0 \mathrm{nA}$ ). Polarization of the cell membrane by applying currents through the recording electrode showed that an IPSP was

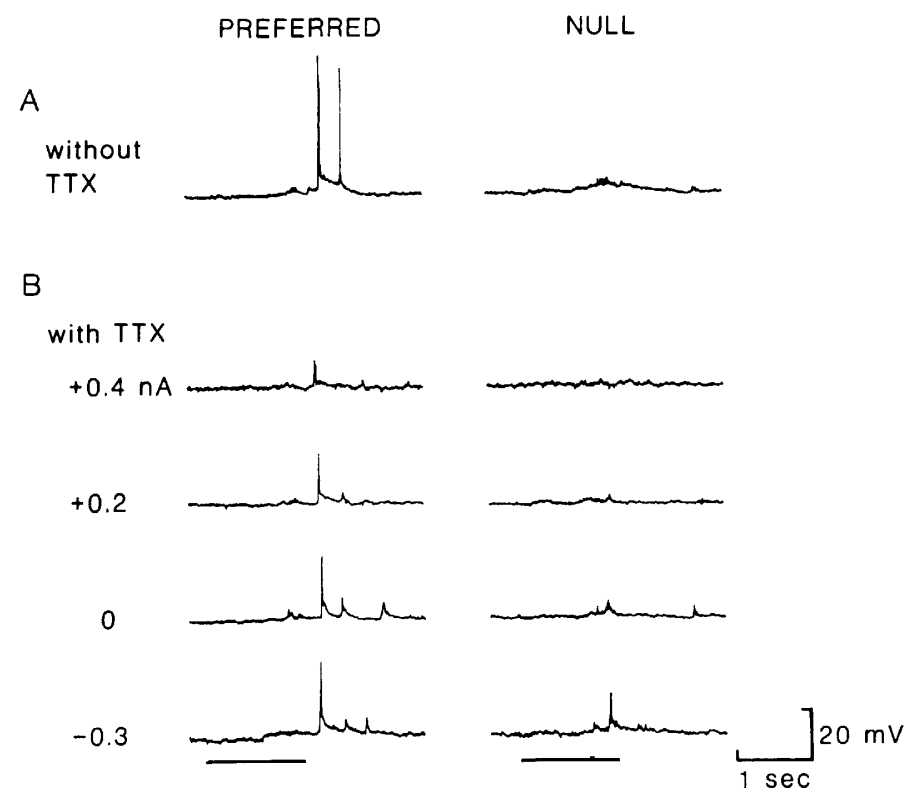

Fig. 8. Responses of a directionally selective OFF-type cell to a bar stimulus $\left(4.2 \mathrm{~mm} \cdot \mathrm{sec}^{-1}\right)$ moving in the preferred (left column) and in the null (right column) directions. A : responses recorded from the retina bathed in the normal Ringer solution. B: responses recorded in the TTX-containing solution. For further explanations, see Fig. 7. 
not contained in either synaptic potential evoked by the preferred or the null movement; the amplitude of the stimulus-induced depolarization was simply reduced when the membrane was depolarized (Fig. $8 \mathrm{~B},+0.2,+0.4 \mathrm{nA}$ ), whereas it was enhanced by membrane hyperpolarization (Fig. $8 \mathrm{~B},-0.3 \mathrm{nA}$ ).

Thus, the synaptic mechanism of directional selectivity of OFF-type cells is similar to that of ON-type cells; the EPSP in the preferred direction was larger in amplitude than that in the null direction.

Among the records of the OFF-type cells, the EPSP's evoked by the null movement frequently appeared earlier than those evoked by the preferred movement ( $c f$. Fig. 8, and the upper records in Fig. 9). This will be discussed later.

\section{Response of directionally selective OFF-type cells to stationary stimulus}

The OFF-type cell in Fig. 9 showed directional selectivity to the moving stimulus (the upper records); to the preferred movement the cell responded with spikes, while only small depolarizations were seen in the null direction. To analyze the receptive field organization, a stationary flashing light bar was presented at various positions of the receptive field in $90 \mu \mathrm{m}$ steps along the preferred-null axis.

The cell gave rise to an OFF-response irrespective of the position of the stimulus, and the receptive field appeared to be almost symmetrical on either side of the preferred-null axis. However, a remarkable difference in latency was revealed when the responses elicited at the respective positions were averaged. Figure 10 illustrates these records by arranging them vertically. OFF-responses to the stationary stimuli presented between 0 and $+360 \mu \mathrm{m}$ had a short latency (about $230 \mathrm{msec}$ ), whereas those produced by the stimuli at the opposite positions had a long latency (about $360 \mathrm{msec}$ ). The latency difference may explain the mechanisms of directional selectivity in the OFF-type cells (see DISCUSSION).

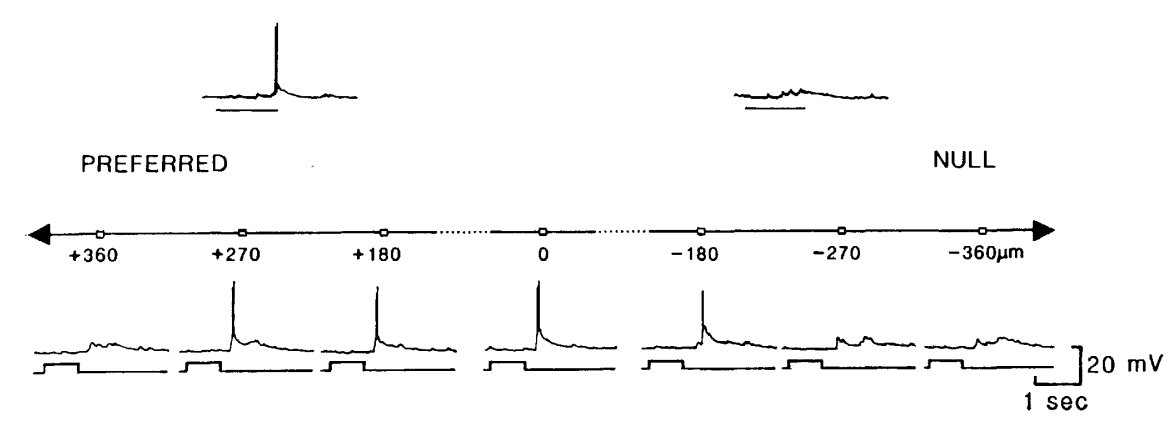

Fig. 9. Responses of a directionally selective OFF-type cell. Upper records: responses to a bar stimulus ( $\left.4.2 \mathrm{~mm} \cdot \mathrm{sec}^{-1}\right)$ moving in the preferred (left record) and in the null direction (right record). Lower records: responses to the stationary flashing bar stimulus presented at various positions of the receptive field. For further explanations, see Fig. 4.

Vol. 34, No. 3, 1984 


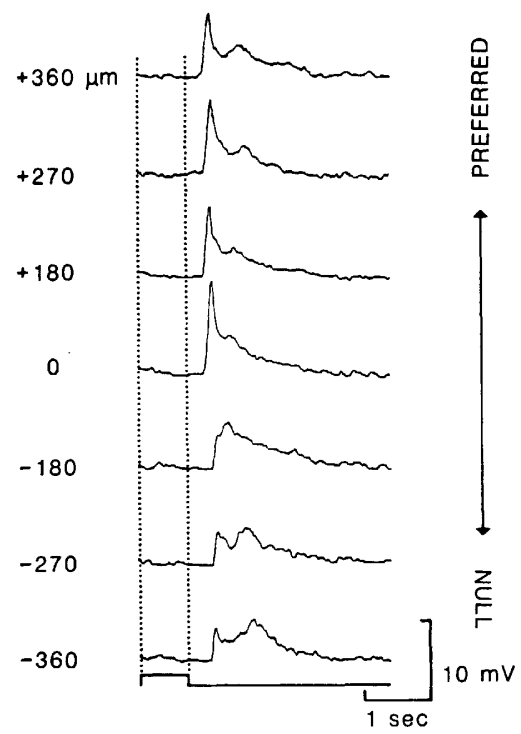

Fig. 10. Averaged responses of the directionally selective OFF-type cell of Fig. 9 to stationary flashing bar stimulus presented at various positions of the receptive field. Five responses were averaged. Other explanations are as in Fig. 5.

\section{DISCUSSION}

Neural mechanisms of directional selectivity of ON-OFF-type cell. A popular hypothesis, proposed by early investigators, for the synaptic mechanism of directional selectivity is as follows: when the stimulus is moved in the preferred direction, excitation occurs prior to inhibition in ganglion cells and evokes spike discharges, while the time sequence of excitation and inhibition is reversed when the stimulus is moved in the null direction, and spike discharges are suppressed (BARlow and LeVICK, 1965; Michael, 1968; WyatT and DAW, 1975; Ariel and DAw, 1982). The intracellular study using the turtle retina by MARCHIAfAVA (1979) supports the above view on the basis of interaction of EPSP and IPSP, although there is no mention of the type of cells used for recording. Our experiment (Fig. 3) showed that in the frog retina this type of synaptic mechanism for directional selectivity can be applied to the ON-OFF-type cell. Our observation that the ON-OFF-type cell contains both EPSP and IPSP inputs is consistent with those of WUNK and WERBLIN (1979) in the tiger salamander retina and of BELGUM et al. (1983) in the mudpuppy retina.

BowLING (1980) has reported that the directionally selective ganglion cell in the turtle retina showed an asymmetrical receptive field when examined with a stationary flashing stimulus. His experiment was carried out by means of extracellular recordings, and accordingly the synaptic mechanism of directional selectivity was still unsettled. In the present experiment, therefore, the organization 
of the receptive field of the ON-OFF-type cell was examined by means of intracellular recordings.

Asymmetrical receptive field organization revealed by the stationary light stimulus (Figs. 4 and 5) may explain the mechanism of directional selectivity. When the light bar enters the receptive field in the preferred direction, the stimulus successively evokes early IPSP's followed by later EPSP's of much larger amplitude. Since the width of the moving light bar is narrow $(300 \mu \mathrm{m})$, the duration of the light stimulus at a given point is so short that ON- and OFF-depolarizations would fuse to form a single depolarization. If the velocity of the stimulus movement is optimal, the synaptic potentials summate to show a biphasic wave form, consisting of an initial small hyperpolarization and a following large depolarization; the latter initiates spike discharges if it reaches the threshold. After the stimulus passes the center of the receptive field, it successively evokes only IPSP's which can summate to produce a sustained hyperpolarization. Therefore, the preferred movement produces a triphasic wave form: an initial small hyperpolarization, a large depolarization, and a late hyperpolarization. When the stimulus is moved in the null direction, the time sequence of the postsynaptic potentials is opposite to that in the preferred direction; a large IPSP precedes an EPSP, thus hindering spike generation.

Neural mechanisms of directional selectivity of $O N$ - and $O F F$-type cells. Unlike the ON-OFF-type cells, ON- and OFF-type cells responded to the moving stimulus solely with EPSP's, whose amplitude evoked by the preferred movement was larger than that produced by the null movement, thus resulting in the directional selectivity (Figs. 7 and 8). BELGUM et al. (1982) reported that in the mudpuppy retina both ON- and OFF-type ganglion cells receive sustained excitatory and inhibitory synaptic inputs, and the balance of these inputs determines the resting potential in darkness, and further that illumination alters the balance of these inputs to produce the light responses. However, our experiment on effects of depolarization of the cell membrane showed that the response evoked by the stimulus movement consisted of only EPSP, and contained no IPSP (Figs. 7 and 8). Therefore, in ON- and OFF-type cells, the directional selectivity is determined by the difference in amplitude of the EPSP's.

In the OFF-type cell, the amplitude difference of EPSP's can result from the difference of response latency which was revealed by the stationary stimulus given at various positions within the receptive field (Fig. 10). If the light stimulus enters the receptive field in the preferred direction, the cell responds with successive OFF-depolarizations. If the velocity of the stimulus movement is optimal, the depolarizations can summate to trigger action potentials. On the contrary, if the stimulus moves in the null direction with the same velocity, the depolarizing responses do not summate, because the velocity mismatches with the latency, which is short when the stimulus is present in the first half of the receptive field, and long in the later half. Only small asynchronous depolarizations with a short latency 
are expected when the stimulus moves in the null direction (Figs. 8 and 9, the upper records). Difference in amplitude of the summated synaptic potentials would cause directional selectivity. The neural circuitry and mechanisms responsible for the latency difference are not yet known. However, it is supposed that the latency difference could be formed presynaptic to the ganglion cell, since at the postsynaptic site it seems unlikely that a single synaptic mechanism (i.e., EPSP) causes the latency difference.

In summary, two different mechanisms of directional selectivity were revealed in the ganglion cells of the frog retina; the first mechanism involves an interaction of EPSP and IPSP occurring at the postsynaptic site of ON-OFF-type cells, and the second mechanism is based on a latency difference of EPSP which is formed presumably presynaptic to the OFF-type cells. However, the mechanism of the directional selectivity in the ON-type cell is still open to future studies.

This work was supported by a Grant-in-Aid for Scientific Research from the Ministry of Education, Science and Culture of Japan (No. 58770116), the Grant for Promotion of Medical Sciences from Keio University School of Medicine, and the Grant from the Keio Health Counselling Center to S.W.; and by a Grant-in-Aid for Scientific Research from the Ministry of Education, Science and Culture of Japan (No. 57480119) to M.M.

\section{REFERENCES}

Ariel, M. and DAW, N. W. (1982) Pharmacological analysis of directionally sensitive rabbit retinal ganglion cells. J. Physiol. (Lond.), 324: 161-185.

BarLow, H. B. and HiLl, R. M. (1963) Selective sensitivity to direction of movement in ganglion cells of the rabbit retina. Science, 139: 412-414.

BARLOW, H. B., HILL, R. M., and LEVICK, W. R. (1964) Retinal ganglion cells responding selectively to direction and speed of image motion in the rabbit. J. Physiol. (Lond.), 173: 377407.

BarLow, H. B. and LeVICK, W. R. (1965) The mechanism of directionally selective units in rabbit's retina. J. Physiol. (Lond.), 178: 477-504.

BAyLOR, D. A. and FetTIPLACE, R. (1979) Synaptic drive and impulse generation in ganglion cells of turtle retina. J. Physiol. (Lond.), 288: 107-127.

Belgum, J. H., Dvorak, D. R., and McReynolds, J. S. (1982) Sustained synaptic input to ganglion cells of mudpuppy retina. J. Physiol. (Lond.), 326: 91-108.

Belgum, J. H., DVoraK, D. R., and McReynolds, J. S. (1983) Sustained and transient synaptic inputs to on-off ganglion cells in the mudpuppy retina. J. Physiol. (Lond.), 340: 599-610.

Bowling, D. B. (1980) Light responses of ganglion cells in the retina of the turtle. J. Physiol. (Lond.), 299: 173-196.

Caldwell, J. H., Daw, N. W., and Wyatt, H. J. (1978) Effects of picrotoxin and strychnine on rabbit retinal ganglion cells: Lateral interactions for cells with more complex receptive fields. J. Physiol. (Lond.), 276: 277-298.

Cleland, B. G. and Levick, W. R. (1974) Properties of rarely encountered types of ganglion cells in the cat's retina and an overall classification. J. Physiol. (Lond.), 240: 457-492.

DACHeux, R. F. (1977) A physiological study of the ontological formation of synaptic interactions in the rabbit retina. Ph. D. Thesis, State University of New York at Buffalo.

HARTLINE, H. K. (1938) The response of single optic nerve fibers of the vertebrate eye to 
illumination of the retina. Am. J. Physiol., 121: 400-415.

Holden, A. L. (1977) Responses of directional ganglion cells in the pigeon retina. J. Physiol. (Lond.), 270: 253-269.

Jensen, R. J. and DeVoe, R.D. (1983) Comparisons of directionally selective with other ganglion cells of the turtle retina: Intracellular recording and staining. J. Comp. Neurol., 217: 271-287.

MarchiafaVA, P. L. (1979) The photoresponses of retinal ganglion cells to stationary and moving visual stimuli. Vision Res., $19: 1203-1211$.

Marchiafava, P. L. and Weiler, R. (1982) The responses of structurally identified amacrine cells in the turtle retina. Proc. R. Soc. Lond. (Biol.), 214: 403-415.

Maturana, H. R., Lettvin, J. Y., McCulloch, W. S., and PitTs, W. H. (1960) Anatomy and physiology of vision in the frog (Rana pipiens). J. Gen. Physiol. (Suppl.), 43: 129-175.

Michael, C. R. (1968) Receptive fields of single optic nerve fibers in a mammal with an all-cone retina. II. Directionally selective units. J. Neurophysiol., 31: 257-267.

Murakami, M. and Shigematsu, Y. (1970) Duality of conduction mechanism in bipolar cells of the frog retina. Vision Res., 10: 1-10.

Murakami, M., Shimoda, Y., Nakatani, K., Miyachi, E., and Watanabe, S. (1982) GabAmediated negative feedback from horizontal cells to cones in carp retina. Jpn. J. Physiol., 32: $911-926$.

Norton, A. L., Spekreijse, H., Wagner, H. G., and Wolbarsht, M. L. (1970) Responses to directional stimuli in retinal preganglionic units. J. Physiol. (Lond.), 206: 93-107.

Oyster, C. W. (1968) The analysis of image motion by the rabbit retina. J. Physiol. (Lond.), 199: 613-635.

Oyster, C. W., TAKAhaShi, E., and CollewiJn, H. (1972) Direction-selective retinal ganglion cells and control of optokinetic nystagmus in the rabbit. Vision Res., 12: 183-193.

Tomita, T., Murakami, M., Hashimoto, Y., and Sasaki, Y. (1961) Electrical activity of single neurons in the frog's retina. In: The Visual System: Neurophysiology and Psychophysics, ed. by Jung, R. and Kornhuber, H., Springer-Verlag, Berlin, pp. 24-30.

WeRBLIN, F. S. (1970) Response of retinal cells to moving spots: Intracellular recording in Necturus maculosus. J. Neurophysiol., 33: 342-350.

WunK, D. F. and Werblin, F. S. (1979) Synaptic inputs to the ganglion cells in the tiger salamander retina. J. Gen. Physiol., 73: 265-286.

WYATT, H. J. and DAW, N. W. (1975) Directionally sensitive ganglion cells in the rabbit retina: Specificity for stimulus direction, size, and speed. J. Neurophysiol., 38: 613-626.

Vol. 34, No. 3, 1984 